\title{
Desires, Need, Perceptions, and Knowledge of Assisted Reproductive Technologies of HIV-Positive Women of Reproductive Age in Ontario, Canada
}

\author{
Yimeng Zhang, ${ }^{1,2}$ Shari Margolese, ${ }^{1}$ Mark H. Yudin, ${ }^{3}$ Janet M. Raboud, ${ }^{4,5}$ Christina Diong, \\ Trevor A. Hart, ${ }^{5,6}$ Heather M. Shapiro, ${ }^{7}$ Cliff Librach, ${ }^{8}$ Matt Gysler, ${ }^{9}$ and Mona R. Loutfy, ${ }^{1,}$ \\ ${ }^{1}$ Women and HIV Research Program, Women's College Research Institute, Women's College Hospital, Toronto, \\ ON, Canada M5G 1 N6 \\ ${ }^{2}$ Faculty of Medicine, University of Toronto, Toronto, ON, Canada M5S 3K1 \\ ${ }^{3}$ Department of Obstetrics and Gynecology, St. Michael's Hospital, University of Toronto, Toronto, ON, Canada M5B 1W8 \\ ${ }^{4}$ Clinical Decision Making and Health Care, University Health Network, Toronto, ON, Canada M5G 2C4 \\ ${ }^{5}$ Dalla Lana School of Public Health, University of Toronto, Toronto, ON, Canada M5S 1A1 \\ ${ }^{6}$ Department of Psychology, Ryerson University, Toronto, ON, Canada M5B 2K3 \\ ${ }^{7}$ Department of Obstetrics and Gynaecology, Mount Sinai Hospital, University of Toronto, Toronto, ON, Canada M5G $1 X 5$ \\ ${ }^{8}$ Department of Obstetrics and Gynaecology, Sunnybrook Health Sciences Centre, University of Toronto, Toronto, \\ ON, Canada M4N 3M5 \\ ${ }^{9}$ Department of Obstetrics and Gynecology, Credit Valley Hospital, Mississauga, ON, Canada L5M 2N1
}

Correspondence should be addressed to Mona R. Loutfy, mona.loutfy@wchospital.ca

Received 12 April 2012; Accepted 3 June 2012

Academic Editors: D. Chen, M. Kühnert, and D. Schust

Copyright (c) 2012 Yimeng Zhang et al. This is an open access article distributed under the Creative Commons Attribution License, which permits unrestricted use, distribution, and reproduction in any medium, provided the original work is properly cited.

The purpose of this cross-sectional study is to assess the desire, need, perceptions, and knowledge of assisted reproductive technologies (ARTs) for women living with HIV (WLWHIV) and determine correlates of ART knowledge desire. WLWHIV of reproductive age were surveyed using the survey instrument "The HIV Pregnancy Planning Questionnaire" at HIV/AIDS service organizations across Ontario, Canada. Of our cohort of 500 WLWHIV, median age was 38, 88\% were previously pregnant, $78 \%$ desired more information regarding ART, 59\% were open to the idea of receiving ART, 39\% felt they could access a sperm bank, and $17 \%$ had difficulties conceiving (self-reported). Age, African ethnicity, and residence in an urban center were correlated with desire for more ART information. Of participants, $50 \%$ wanted to speak to an obstetrician/gynecologist regarding pregnancy planning, and $74 \%$ regarded physicians as a main source of fertility service information. While the majority of participants in our cohort desire access to ART information, most do not perceive these services as readily accessible. Healthcare practitioners were viewed as main sources of information regarding fertility services and need to provide accurate information regarding access. Fertility service professionals need to be aware of the increasing demand for ART among WLWHIV.

\section{Introduction}

With the advent of highly active antiretroviral therapy (HAART) to treat HIV infection over the past 15 years, dramatic reductions in HIV-related morbidity and mortality have yielded improvements in quality of life and life expectancy [1]. The risk of vertical transmission through pregnancy has also been reduced to $<1 \%$ with timely antiretroviral therapy, continuing viral suppression, delivery by Caesarean section if appropriate, and avoidance of breastfeeding [2]. Women now represent 22\% of Canada's HIV-positive population, and with over $80 \%$ of HIVpositive women being of reproductive age [3], there is a need for safe pregnancy planning as more women living with HIV (WLWHIV) desire to become pregnant. While prevention of vertical transmission of HIV to the child remains a key component, the main focus of safe pregnancy planning includes prevention of horizontal transmission to 
an uninfected partner and treatment of infertility issues [4]. To achieve such objectives, assisted reproductive technologies (ARTs) have become central to meeting the reproductive needs of WLWHIV in resource-rich countries.

Indeed, access to conception and fertility services including ART has become an important component within the recent global movements to establish national guidelines or update existing recommendations on pregnancy planning and conception for people living with HIV (PLWHIV) in Canada, the United Kingdom, Germany, and France [5-11]. Furthermore, as of July 2010, the most recent American Society for Reproductive Medicine (ASRM) Ethics Committee guidelines also recommend that fertility clinics offer services to HIV-positive individuals and couples willing to use ART for reduction of transmission risk [12]. Compared to conception through unprotected intercourse with timed ovulation, associated with a horizontal transmission risk of $4.3 \%$ for serodiscordant couples [13], ART procedures such as sperm washing, intra uterine insemination (IUI), in vitro fertilization (IVF), and intracytoplasmic sperm injection (ICSI) have been found to offer significant reductions in horizontal HIV transmission or coinfection for couples wishing to conceive [13]. As well, ART is also recommended for the treatment of infertility, an issue of importance to WLWHIV as studies have indicated lower fertility rates among HIV-positive women [14-22]. Various studies have documented an increased rate of tubal factor infertility in HIV-positive women $[7,14,15,23]$.

Previous literature on the fertility intentions of WLWHIV has been important in eliciting trends and predictors of the decision to attempt pregnancy [24-39]. As well, studies exist regarding the prevalence of fertility service centers in North America receiving requests from or providing services to PLWHIV $[6,12,31]$. Although the ASRM guidelines recommend that fertility clinics offer reproductive assistance to HIV-positive patients within technical and economic feasibility, less than $3 \%$ of fertility practices registered with the American Society for Assisted Reproductive Technologies provide services to couples where both partners are HIV positive [12,31]. Low patient volume has been cited as the most common reason for the limitation of fertility services by American service providers [31]. Few studies have investigated the demand for or desire to use ART or the trends in and predictors of conception strategies amongst PLWHIV. As women are the main recipients of ART, it is important to assess the current intentions, knowledge, and perceptions regarding ART among the current cohort of WLWHIV in North America. The purpose of this cross-sectional study was to assess the desire and need for ART among HIV-positive women of reproductive age living in Ontario, Canada, and to determine correlates of ART knowledge desire and the knowledge and perceptions of accessibility of ART by the WLWHIV in this cohort.

\section{Materials and Methods}

2.1. Study Design and Population. A cross-sectional study using a survey instrument was carried out with participants who met the following inclusion criteria: (1) HIV-positive, (2) biologically female, (3) of reproductive age (ages 18-52), (4) living in Ontario, Canada, and (5) ability to read English or French. The upper age limit was chosen to reflect the cut-off for fertility clinic consultation in Canada. The details of the original cross-sectional study have been previously described [40].

2.2. Recruitment and Ethics. Recruitment was conducted from October 5th, 2007 to March 31st, 2009 through 28 AIDS service organizations (ASOs), eight primary care and specialty HIV clinics, and two community health centers (CHCs) across the province of Ontario. An invitation email was sent out to all Ontario ASOs listed on the Canadian AIDS Society website (the national society for ASOs) and all clinics and CHCs known by the investigators that care for HIV-positive women. Recruitment and study qualification determination were carried out by a single research staff member at each site following a predeveloped recruitment plan (available upon request) [40]. The recruitment was carried out in a consecutive manner. Our study determined geographic distribution of our data collection sites based on the provincial regions laid out by the provincial public health authorities with the specific regions noted in Table 1. This nonrandom sampling technique was used in an effort to obtain a representative sample of HIV-positive women of reproductive age living in Ontario in the absence of a registry of HIV-positive individuals. Once written consent was obtained, the survey was completed at the site or at home.

Research Ethics Board approval was obtained prior to study initiation. Written informed consent was obtained from every participant. An amended ethics approval was obtained for this specific research analysis.

2.3. Survey Instrument and Validation. A 189-item survey instrument, "The HIV Pregnancy Planning Questionnaire," was created using the methods of Fowler for instrument development [41] and has previously been described in detail [40]. The survey consisted of 12 domains including: (1) interest/desire to have children, (2) intent to have children in the future, (3) behavior related to the pursuit of fertility, (4) menstrual, birth control, and sexual history, (5) pregnancy and birth history, (6) perceived support for becoming pregnant, (7) satisfaction with providers, (8) needs assessment, (9) HIV medical history, (10) demographics, (11) anxiety and depression, and (12) HIV stigma (full survey instrument available upon request).

The survey was first developed in English and then translated into French using the back translation method [40]. Content validity was achieved by using items from 4 previously validated surveys $[13,24,32,42]$, by developing items based on a literature search exploring factors that determined reproductive decisions in HIV-positive women (9-39) and by reviewing the questions with a project advisory panel of experts including HIV specialists, obstetricians, midwives, community members, and PLWHIV. Face validity was achieved by initially piloting the survey with 
TABle 1: Demographic characteristics of study participants.

\begin{tabular}{|c|c|}
\hline Characteristics & $N=490$ \\
\hline Age (years): median (IQR) & $38(32,43)$ \\
\hline $18-25$ & $28(6 \%)$ \\
\hline $26-40$ & $269(57 \%)$ \\
\hline$>40$ & $179(38 \%)$ \\
\hline \multicolumn{2}{|l|}{ Ethnic background: $N(\%)$} \\
\hline African & $217(46 \%)$ \\
\hline Caribbean & $56(12 \%)$ \\
\hline European-British & $57(12 \%)$ \\
\hline French-Canadian & $52(11 \%)$ \\
\hline Aboriginal & $40(9 \%)$ \\
\hline Other & $48(10 \%)$ \\
\hline \multicolumn{2}{|l|}{ Birth place: $N(\%)$} \\
\hline Africa & $209(44 \%)$ \\
\hline Canada & $187(39 \%)$ \\
\hline Caribbean & $49(10 \%)$ \\
\hline Other & $32(7 \%)$ \\
\hline Not Born in Canada: $N(\%)$ & $290(61 \%)$ \\
\hline Years in Canada: median (IQR) & $5(2,13)$ \\
\hline \multicolumn{2}{|l|}{ Region in Ontario: $N(\%)$} \\
\hline Toronto & $253(52 \%)$ \\
\hline Ottawa & $64(13 \%)$ \\
\hline Other & $173(35 \%)$ \\
\hline \multicolumn{2}{|l|}{ Sexual orientation: $N(\%)$} \\
\hline Heterosexual & $408(89 \%)$ \\
\hline Lesbian/Bisexual & $43(9 \%)$ \\
\hline Other & $8(2 \%)$ \\
\hline \multicolumn{2}{|l|}{ Work: $N(\%)$} \\
\hline Working & $184(39 \%)$ \\
\hline On government assistance & $235(49 \%)$ \\
\hline \multicolumn{2}{|l|}{ Marital status: $N(\%)$} \\
\hline Married/common-law/living with a partner & $210(46 \%)$ \\
\hline Divorced/widowed & $113(25 \%)$ \\
\hline Never married & $135(29 \%)$ \\
\hline \multicolumn{2}{|l|}{ Education: $N(\%)$} \\
\hline High school or higher & $296(69 \%)$ \\
\hline Less than high school & $133(31 \%)$ \\
\hline \multicolumn{2}{|l|}{ Annual household income: $N(\%)$} \\
\hline$<20 \mathrm{~K}$ & $189(46 \%)$ \\
\hline $20-40 \mathrm{~K}$ & $124(30 \%)$ \\
\hline$>40 \mathrm{~K}$ & $94(23 \%)$ \\
\hline \multicolumn{2}{|l|}{ Clinical characteristics } \\
\hline $\begin{array}{l}\text { Duration of HIV diagnosis (years): median } \\
\text { (IQR) }\end{array}$ & $7.0(4.0,12.0)$ \\
\hline Hepatitis B coinfected: $N(\%)$ & $16(3 \%)$ \\
\hline Hepatitis C co-infected: $N(\%)$ & $67(14 \%)$ \\
\hline Recent CD4 count: median (IQR) & $466(320,685)$ \\
\hline
\end{tabular}

TABle 1: Continued.

\begin{tabular}{lc}
\hline Characteristics & $N=490$ \\
\hline$\geq 200$ cells $/ \mathrm{mm}^{3}: N(\%)$ & $315(90 \%)$ \\
Recent VL( $\log _{10}$ copies/mL): median (IQR) & $3.8(2.9,4.5)$ \\
Ever on HIV Medication: $N(\%)$ & $414(86 \%)$ \\
Currently on HIV treatment: $N(\%)$ & $356(74 \%)$ \\
Years on treatment: median (IQR) & $4.5(1.9,9.1)$ \\
Sexual history & \\
Partner: $N$ (\%) & \\
$\quad$ HIV negative & $162(33 \%)$ \\
$\quad$ HIV positive & $118(24 \%)$ \\
$\quad$ No partner & $160(33 \%)$ \\
$\quad$ Unknown & $44(9 \%)$ \\
In sexual relationship: $N(\%)$ & $265(55 \%)$ \\
Monogamous relations: $N(\%)$ & $250(51 \%)$ \\
Current contraceptive use: $N(\%)$ & $172(36 \%)$ \\
Fertility history: $N$ (\%) & \\
Ever had pregnancies & $422(88 \%)$ \\
Ever gave birth & $358(74 \%)$ \\
\hline IDU: injection drug use; VL: viral load. &
\end{tabular}

20 HIV-positive women in 2 focus groups. The focus group participants confirmed that the survey instrument items actually appeared to be measuring the intended items related to the domains. Furthermore, participants were asked to comment on each item in terms of comprehension, clarity, and relevance. Further pilot testing was carried out with an initial 52 HIV-positive women that met the inclusion criteria.

2.4. Statistical Analysis. Baseline characteristics of the study population were summarized using medians and interquartile ranges (IQRs) for continuous variables and frequencies and proportions for categorical variables. The geographic distribution of the study population was compared to the distribution of HIV-positive women living in Ontario using the Chi-square test.

The primary outcome of interest for this analysis was desire for information about ART (ART knowledge desire). The question used to represent desire for ART information was "I would like to learn more about fertility technologies and options for people living with HIV." The response options characterized agreement with the statement on a Likert-type scale. Participant responses were dichotomized into "Yes" or "No" with regard to desire for ART. Participant answers of "Strongly agree" or "Agree" were classified as "Yes"; participant answers of "Strongly disagree" or "Disagree" or "Neither" were classified as "No". The dichotomized participant responses were compared across the various demographic variables. The secondary outcome of interest for this analysis was past need for ART. The question used to represent previous need for ART was "If you have been pregnant before, did you ever experience problems or difficulties in trying to get pregnant?" Women who had 
never been pregnant and women who had been pregnant but did not answer this question were excluded from the analysis. Participant responses were compared across the various demographic variables. Univariate logistic regression analysis was conducted to determine the unadjusted odds ratios with 95\% CIs for correlates of the desire for ART and need for ART. The final multivariate logistic regression model determined the adjusted odds ratios with 95\% confidence intervals (CIs) for correlates of the desire for ART and need for ART. The final multivariable logistic regression models included covariates that were a priori believed to be related to desire for ART and need for ART, such as age, ethnic background, marital status, history of HIV medication, and current contraceptive use. Variables which were significant at $P<0.20$ in the univariate analyses were candidates for inclusion in final multivariable logistic regression models for desire and need for ART. When multiple covariates measured similar phenomenon (e.g., ethnic background and country of birth), the variable representing each construct with the most statistical significance was chosen. Finally, the qualifying variables were entered into the multivariable model and selected by stepwise-selection method. Only the correlates with a significant effect $(P<0.05)$ remained in the final multivariable models.

Other outcomes of interest included perceptions and knowledge of ART. The outcomes were reported using medians and IQR for continuous variables and proportions for categorical variables. Survey data was entered twice and verified prior to analysis. Statistical analyses were performed using SAS Version 9.2 (SAS Institute, Cary, NC, USA).

\section{Results}

3.1. Study Population. Five hundred and four WLWHIV in Ontario, Canada, were recruited from 38 sites. Of these participants, four did not meet the inclusion criteria (two were over the age of 52 and two were not living in Ontario). Of the remaining 500 participants, 10 did not answer the question used to represent desire for ART. Surveys from the remaining 490 participants were used for the final analysis for the primary outcome.

The median age for this final study population was 38 years (IQR 32, 43). Sixty-one percent of the participants were born outside of Canada and $46 \%$ were of African ethnicity. Within this cohort, 55\% were in sexual relationships and $46 \%$ were married, common-law, or living with a partner. Thirty-three percent of the women had HIV-negative partners and 24\% had HIV-positive partners; $36 \%$ were currently using contraception; $88 \%$ had been pregnant previously; $74 \%$ had given birth. The demographic characteristics of the entire study population are presented in Table 1.

3.2. ART Knowledge Desire. In the final study population of 490 HIV-positive women living in Ontario, Canada, 78\% $(n=384)$ indicated that they would like to learn more about fertility technology options. The distribution of participant characteristics by desire for ART information is shown in the logistic regression models for correlates of desire for ART in Table 2. In the final multivariate model, African ethnicity $(\mathrm{OR}=3.86, P<0.0001)$ and current contraceptive use (OR =1.70, $P=0.05)$ were associated with a desire for ART. Being married, common-law, or living with a partner (OR $=0.52, P=0.04)$ and history of HIV medication $(\mathrm{OR}=0.34$, $P=0.02$ ) were associated with a lack of desire for ART.

3.3. HIV-Positive Women's Need for ART. Study participants were also assessed for previous need for ART. Of the 500 participants who met the study inclusion criteria, 65 did not answer the question used to represent need for ART and 10 had never been pregnant. The final analysis included surveys from 425 participants.

The distribution of participant characteristics by need for ART is shown in the logistic regression models for correlates of need for ART in Table 3. For the study participants, 17\% $(n=72)$ indicated they had difficulties getting pregnant. In the final multivariate model, annual household income of $\$ 20,000$ to $\$ 40,000$ ( $\mathrm{OR}=2.36, P=0.02$ ) greater than $\$ 40,000(\mathrm{OR}=2.63, P=0.01)$ and current HIV treatment $(\mathrm{OR}=2.53, P=0.01)$ were associated with difficulties conceiving and two or more lifetime pregnancies $(\mathrm{OR}=0.41$, $P<0.01)$ were associated with no difficulties conceiving.

3.4. Perceptions and Knowledge of ART. Study participants were also assessed for perceptions towards and knowledge of ART. The final analysis included surveys from the 500 participants who met the study inclusion criteria and responded to these set of questions. The distribution of participant answers to the various questions representing perceptions towards and knowledge of ART is shown in Table 4.

The majority of participants (59\%) were open to medical techniques that help with conception and 39\% felt they could access a sperm bank if needed. Of the women surveyed, $74 \%$ agreed they could ask a physician if they needed help finding a fertility clinic. To help with the decision to become pregnant, $50 \%$ of the participants indicated they wanted information booklets and publications on becoming pregnant, 59\% wanted to speak to a health professional with fertility expertise, and $50 \%$ wanted to speak to an obstetrician/gynecologist.

\section{Discussion}

In this study, a large majority of WLWHIV (78\%) indicated a desire for information regarding reproductive technology options. Correlates of desire for ART, a measure of pregnancy intention, included younger age, ethnicity, residence in an urban region, and birth place outside of Canada. Previous publications support our findings of younger age and Black/African ethnicity as significant correlates of pregnancy intention in WLWHIV $[26,28,29,34,35,39,43,44]$. Although African ethnicity has not been associated with desire to have children, women of African ethnicity may be more likely to intend pregnancy due to cultural factors and traditional gender roles that stress the importance of childbearing [44-47]. History of HIV medication use was 
TABLE 2: Univariate and multivariate logistic regression models of participant responses for desire for ART information.

\begin{tabular}{|c|c|c|c|c|c|c|}
\hline \multirow{2}{*}{ Characteristics } & \multicolumn{2}{|c|}{ ART intentions } & \multicolumn{2}{|l|}{ Unadjusted } & \multicolumn{2}{|l|}{ Adjusted } \\
\hline & Yes $(n=384)$ & No $(n=106)$ & Odds ratio (95\% CIs) & $P$ value & Odds ratio (95\% CIs) & $P$ value \\
\hline \multicolumn{7}{|l|}{ Age (years): } \\
\hline $18-25$ & $20(5 \%)$ & $8(8 \%)$ & 1 & & 1 & \\
\hline $26-40$ & $231(62 \%)$ & $38(36 \%)$ & $2.43(0.99,5.91)$ & 0.05 & $2.51(0.93,6.75)$ & 0.07 \\
\hline$>40$ & $120(32 \%)$ & $59(56 \%)$ & $0.81(0.34,1.96)$ & 0.64 & $0.78(0.29,2.11)$ & 0.63 \\
\hline \multicolumn{7}{|l|}{ Ethnic background } \\
\hline African & $197(53 \%)$ & $20(20 \%)$ & $4.47(2.63,7.61)$ & $<0.0001$ & $3.86(2.16,6.92)$ & $<0.0001$ \\
\hline Other & $174(47 \%)$ & $79(80 \%)$ & 1 & & 1 & \\
\hline \multicolumn{7}{|l|}{ Birth place } \\
\hline Africa & $187(50 \%)$ & $22(21 \%)$ & 1 & & & \\
\hline Canada & $126(34 \%)$ & $61(58 \%)$ & $0.24(0.14,0.42)$ & $<0.0001$ & & \\
\hline Caribbean & $36(10 \%)$ & $13(12 \%)$ & $0.33(0.15,0.71)$ & $<0.01$ & & \\
\hline Other & $23(6 \%)$ & $9(9 \%)$ & $0.30(0.12,0.73)$ & $<0.01$ & & \\
\hline Not born in Canada & $246(64 \%)$ & $44(42 \%)$ & $2.51(1.62,3.90)$ & $<0.0001$ & & \\
\hline $\begin{array}{l}\text { Years in Canada (for those not } \\
\text { born in Canada) }\end{array}$ & $4.8(2.0,11.0)$ & $10.0(3.3,25.0)$ & $0.95(0.92,0.97)$ & $<0.001$ & & \\
\hline Toronto region & $210(55 \%)$ & $43(41 \%)$ & $1.77(1.14,2.74)$ & 0.01 & & \\
\hline Working & $142(38 \%)$ & $42(42 \%)$ & $0.86(0.55,1.34)$ & 0.51 & & \\
\hline On government assistance & $189(51 \%)$ & $46(46 \%)$ & $1.22(0.79,1.90)$ & 0.37 & & \\
\hline \multicolumn{7}{|l|}{ Marital status } \\
\hline $\begin{array}{l}\text { Married/common-law/living } \\
\text { with a partner }\end{array}$ & $154(43 \%)$ & $56(57 \%)$ & $0.48(0.27,0.84)$ & 0.01 & $0.52(0.27,0.97)$ & 0.04 \\
\hline Divorced/widowed & $91(25 \%)$ & $22(22 \%)$ & $0.72(0.37,1.40)$ & 0.33 & $0.84(0.39,1.79)$ & 0.64 \\
\hline Never married & $115(32 \%)$ & $20(20 \%)$ & 1 & & 1 & \\
\hline \multicolumn{7}{|l|}{ Education } \\
\hline High school or higher & $239(71 \%)$ & $57(63 \%)$ & $1.44(0.89,2.34)$ & 0.14 & & \\
\hline Less than high school & $99(29 \%)$ & $34(37 \%)$ & 1 & & & \\
\hline \multicolumn{7}{|l|}{ Annual household income } \\
\hline$<20 \mathrm{~K}$ & $149(47 \%)$ & $40(44 \%)$ & 1 & & & \\
\hline $20-40 \mathrm{~K}$ & $107(34 \%)$ & $17(19 \%)$ & $1.69(0.91,3.14)$ & 0.10 & & \\
\hline$>40 \mathrm{~K}$ & $60(19 \%)$ & $34(37 \%)$ & $0.47(0.27,0.82)$ & $<0.01$ & & \\
\hline $\begin{array}{l}\text { Years since diagnosis of HIV } \\
\text { positive }\end{array}$ & $6(3,11)$ & $10(5,16)$ & $0.93(0.89,0.97)$ & $<0.001$ & & \\
\hline Hepatitis B co-infected & $16(4 \%)$ & $0(0 \%)$ & $\S$ & & & \\
\hline Hepatitis C co-infected & $52(14 \%)$ & $15(15 \%)$ & $0.96(0.52,1.79)$ & 0.91 & & \\
\hline $\mathrm{CD} 4 \geq 200$ cells $/ \mathrm{mm}^{3}$ & $248(91 \%)$ & $67(88 \%)$ & $1.28(0.57,2.86)$ & 0.55 & & \\
\hline Recent VL $\left(\log _{10}\right.$ copies/mL) & $3.8(2.9,4.6)$ & $3.9(2.8,4.5)$ & $0.93(0.55,1.59)$ & 0.80 & & \\
\hline Ever on HIV medication & $315(83 \%)$ & $99(94 \%)$ & $0.30(0.13,0.72)$ & $<0.01$ & $0.34(0.14,0.85)$ & 0.02 \\
\hline Currently on HIV treatment & $276(74 \%)$ & $80(77 \%)$ & $0.84(0.50,1.39)$ & 0.49 & & \\
\hline \multicolumn{7}{|l|}{ Partner } \\
\hline HIV negative & $125(58 \%)$ & $37(59 \%)$ & 1 & & & \\
\hline HIV positive & $92(42 \%)$ & $26(41 \%)$ & $1.05(0.59,1.85)$ & 0.87 & & \\
\hline In sexual relationship & $205(54 \%)$ & $60(57 \%)$ & $0.88(0.57,1.37)$ & 0.58 & & \\
\hline
\end{tabular}


TABle 2: Continued.

\begin{tabular}{|c|c|c|c|c|c|c|}
\hline \multirow{2}{*}{ Characteristics } & \multicolumn{2}{|c|}{ ART intentions } & \multicolumn{2}{|l|}{ Unadjusted } & \multicolumn{2}{|l|}{ Adjusted } \\
\hline & Yes $(n=384)$ & No $(n=106)$ & Odds ratio (95\% CIs) & $P$ value & Odds ratio (95\% CIs) & $P$ value \\
\hline Monogamous relations & $193(51 \%)$ & $57(54 \%)$ & $0.86(0.56,1.33)$ & 0.51 & & \\
\hline Current contraceptive use & $124(33 \%)$ & $48(45 \%)$ & $0.60(0.39,0.93)$ & 0.02 & $1.70(1.00,2.88)$ & 0.05 \\
\hline \multicolumn{7}{|l|}{ Fertility history: } \\
\hline Ever had pregnancies & $327(87 \%)$ & $95(90 \%)$ & $0.70(0.34,1.44)$ & 0.33 & & \\
\hline Ever gave birth & $279(74 \%)$ & $79(75 \%)$ & $0.95(0.57,1.56)$ & 0.83 & & \\
\hline
\end{tabular}

$\S$ Odds ratio not available. IDU: injection drug use; VL: viral load.

also associated with a lack of desire for ART in our study. However, other studies have indicated a positive influence on childbearing decisions associated with HAART [27, 30, $32,33,35]$. These other studies, conducted in Vietnam, India, and South Africa, may have reflected the more advanced disease of the study populations, where HAART access is associated with better health and greater perceived ability to be a fit parent. In direct contrast to a previous study in British Columbia (BC), Canada, being in a stable relationship was associated with a lack of desire for ART in our study. This discrepancy can be attributed to the epidemiology of HIV infection in BC, differences in sample characteristics of the study, and the location and timing of the recruitment process [28]. These differences highlight potential regional differences in the reproductive concerns of WLWHIV, attitudes towards those seeking ART, and a need for continued research in this area.

In addition to desire, our study also investigated potential need for reproductive technology options among WLWHIV by assessing correlates of self-reported conception difficulty. Although not a direct measure of the true infertility rates among WLWHIV, conception difficulty does provide an estimate of the prevalence of infertility concerns within the population. Infertility, defined as inability to conceive 12 months after initiating attempts, affects $10-15 \%$ of the general population [48]. Various previous studies have documented the lower fertility rates of WLWHIV [14-23] and the percentage of WLWHIV who reported difficulties conceiving in our study (17\%) was higher than that found in general population. This percentage is higher even though the primary infertility of our participants did resolve. WLWHIV with resolved primary infertility are not reflective of the population of WLWHIV and our results may underestimate the true infertility rates of WLWHIV. It appears then that the potential need for ART among WLWHIV may be higher than that of the general population. Greater household income and current HIV treatment were both correlates of difficulty conceiving, potentially due to the association between higher income and age. However, age was not a correlate of conception difficulty in our study. The lack of association between age, a major predictor of infertility generally, and difficulty conceiving in this study may be attributed to the relative youth of the study population. The age range of study participants was $32-43$, and previous attempts at pregnancy may have occurred when the participants were younger
( $<35$ years) when age did not significantly affect fertility. Current HIV treatment, while associated with increased fertility in developing countries [27, 30, 32, 33, 35], was associated with difficulties conceiving in our study. Thus far, studies on the effects of HAART on pregnancy rates have not shown conclusive evidence of any impact on fertility [49-51]. More research is required to further evaluate the true effects of HAART on the fertility of WLWHIV.

This study also assessed the perceptions and knowledge of WLWHIV of ART. In our study, at least half of the participants viewed information booklets and publications on becoming pregnant, speaking with a health care professional with fertility expertise, or speaking with a obstetrician/gynecologist as important resources needed to help with the decision to become pregnant. More than one-third of participants also indicated a desire to have access to a fertility clinic as a resource needed for making pregnancy decisions. The majority of women surveyed were open to receiving ART but only $39 \%$ of participants believed they had access to ART services such as sperm banks. It appears that although women are interested in pursuing ART services, most do not perceive these services as being accessible. Since $74 \%$ of study participants indicated they regard their physician as the first source of information for ART, doctors therefore have an important role in informing their patients of their full reproductive options. With the current movement towards increasing provision of ART to PLWHIV for prevention of horizontal transmission and treatment of subfertility, there is an increased need for physicians to provide information and initiate discussions regarding pregnancy planning and conception to their patients who are HIV positive.

The assessment of ART desires of a cohort of WLWHIV in Ontario, Canada, has important implications for healthcare providers, policy makers, and researchers. The results of this survey indicate WLWHIV of reproductive age are open to and desire access to ART for the purposes of safe conception and treatment of infertility. While this desire and demand for fertility technology options is supported by ASRM Ethics Committee [12] guidelines for safe pregnancy planning in North America, access to fertility services remains a limiting factor in the provision of reproductive care for WLWHIV. Although the majority of fertility clinics surveyed across Canada and the US have expressed willingness to provide care to HIV-positive individuals, less than $50 \%$ have actually offered treatment $[31,52]$. 
TABLE 3: Univariate and multivariate logistic regression models of participant responses for need for ART.

\begin{tabular}{|c|c|c|c|c|c|c|}
\hline \multirow{2}{*}{ Characteristics } & \multicolumn{2}{|c|}{ Problems becoming pregnant } & \multicolumn{2}{|l|}{ Unadjusted } & \multicolumn{2}{|l|}{ Adjusted } \\
\hline & Yes $(n=72)$ & No $(n=353)$ & Odds ratio (95\% CIs) & $P$ value & Odds ratio (95\% CIs) & $P$ value \\
\hline Age (years) & $38(33,43)$ & $38(33,44)$ & & & & \\
\hline $18-25$ & $2(3 \%)$ & $18(5 \%)$ & 1 & & 1 & \\
\hline $26-40$ & $44(64 \%)$ & $181(53 \%)$ & $2.19(0.49,9.78)$ & 0.31 & $1.60(0.33,7.69)$ & 0.56 \\
\hline$>40$ & $23(33 \%)$ & $144(42 \%)$ & $1.44(0.31,6.61)$ & 0.64 & $1.13(0.23,5.59)$ & 0.88 \\
\hline \multicolumn{7}{|l|}{ Ethnic background } \\
\hline African & $25(35 \%)$ & $168(50 \%)$ & 1 & & & \\
\hline Caribbean & $7(10 \%)$ & $33(10 \%)$ & $1.43(0.57,3.57)$ & 0.45 & & \\
\hline European-British & $10(14 \%)$ & $33(10 \%)$ & $2.04(0.89,4.64)$ & 0.09 & & \\
\hline French-Canadian & $11(15 \%)$ & $38(11 \%)$ & $1.95(0.88,4.29)$ & 0.10 & & \\
\hline Aboriginal & $8(11 \%)$ & $30(9 \%)$ & $1.79(0.74,4.35)$ & 0.20 & & \\
\hline Other & $10(14 \%)$ & $35(10 \%)$ & $1.92(0.85,4.35)$ & 0.12 & & \\
\hline African ethnicity versus other & & & $0.55(0.32,0.93)$ & 0.03 & & \\
\hline \multicolumn{7}{|l|}{ Birth place } \\
\hline Africa & $26(37 \%)$ & $161(47 \%)$ & 1 & & & \\
\hline Canada & $34(48 \%)$ & $126(37 \%)$ & $1.67(0.95,2.93)$ & 0.07 & & \\
\hline Caribbean & $7(10 \%)$ & $30(9 \%)$ & $1.44(0.58,3.63)$ & 0.43 & & \\
\hline Other & $4(6 \%)$ & $25(7 \%)$ & $0.99(0.32,3.08)$ & 0.99 & & \\
\hline Not born in Canada & $37(51 \%)$ & $216(61 \%)$ & $0.67(0.40,1.12)$ & 0.12 & & \\
\hline $\begin{array}{l}\text { Years in Canada (for those not } \\
\text { born in Canada) }\end{array}$ & $8(3,17)$ & $5(2,11)$ & $1.03(0.99,1.06)$ & 0.13 & & \\
\hline Toronto region & $33(46 \%)$ & $181(51 \%)$ & $0.80(0.48,1.34)$ & 0.40 & & \\
\hline Working & $27(39 \%)$ & $129(38 \%)$ & $1.04(0.61,1.77)$ & 0.88 & & \\
\hline On government assistance & $36(51 \%)$ & $172(50 \%)$ & $1.05(0.63,1.76)$ & 0.84 & & \\
\hline \multicolumn{7}{|l|}{ Marital status } \\
\hline $\begin{array}{l}\text { Married/common-law/living } \\
\text { with a partner }\end{array}$ & $34(50 \%)$ & $152(46 \%)$ & $1.08(0.57,2.05)$ & 0.82 & & \\
\hline Divorced/widowed & $17(25 \%)$ & $96(29 \%)$ & $0.85(0.41,1.78)$ & 0.67 & & \\
\hline Never married & $17(25 \%)$ & $82(25 \%)$ & 1 & & & \\
\hline \multicolumn{7}{|l|}{ Education } \\
\hline High school or higher & $43(69 \%)$ & $204(66 \%)$ & $1.14(0.63,2.06)$ & 0.66 & & \\
\hline Less than high school & $19(31 \%)$ & $103(34 \%)$ & 1 & & & \\
\hline \multicolumn{7}{|l|}{ Annual household income } \\
\hline$<20 \mathrm{~K}$ & $19(30 \%)$ & $150(51 \%)$ & 1 & & 1 & \\
\hline $20-40 \mathrm{~K}$ & $23(37 \%)$ & $85(29 \%)$ & $2.14(1.10,4.15)$ & 0.02 & $2.36(1.16,4.80)$ & 0.02 \\
\hline$>40 \mathrm{~K}$ & $21(33 \%)$ & $60(20 \%)$ & $2.76(1.39,5.50)$ & $<0.01$ & $2.63(1.25,5.52)$ & 0.01 \\
\hline $\begin{array}{l}\text { Years since diagnosis of HIV } \\
\text { positive }\end{array}$ & $9(4,13)$ & $7(4,12)$ & $1.00(0.99,1.01)$ & 0.74 & & \\
\hline Hepatitis B co-infection & $3(4 \%)$ & $9(3 \%)$ & $1.60(0.42,6.08)$ & 0.49 & & \\
\hline Hepatitis C co-infection & $11(15 \%)$ & $54(16 \%)$ & $0.96(0.47,1.94)$ & 0.90 & & \\
\hline $\mathrm{CD} 4 \geq 200$ cells $/ \mathrm{mm}^{3}$ & $55(92 \%)$ & $220(90 \%)$ & $1.25(0.46,3.41)$ & 0.66 & & \\
\hline Recent VL ( $\log _{10}$ copies/mL) & $4(4,5)$ & $4(3,4)$ & $1.90(0.91,3.97)$ & 0.09 & & \\
\hline Ever on HIV medication & $67(93 \%)$ & $297(85 \%)$ & $2.30(0.88,5.98)$ & 0.09 & & \\
\hline Currently on HIV treatment & $62(86 \%)$ & $248(72 \%)$ & $2.40(1.18,4.87)$ & 0.02 & $2.53(1.12,5.71)$ & 0.03 \\
\hline
\end{tabular}


TABle 3: Continued.

\begin{tabular}{|c|c|c|c|c|c|c|}
\hline \multirow{2}{*}{ Characteristics } & \multicolumn{2}{|c|}{ Problems becoming pregnant } & \multicolumn{2}{|l|}{ Unadjusted } & \multicolumn{2}{|l|}{ Adjusted } \\
\hline & Yes $(n=72)$ & No $(n=353)$ & Odds ratio (95\% CIs) & $P$ value & Odds ratio (95\% CIs) & $P$ value \\
\hline \multicolumn{7}{|l|}{ Partner } \\
\hline HIV negative & $27(66 \%)$ & $105(53 \%)$ & 1 & & & \\
\hline HIV positive & $14(34 \%)$ & $92(47 \%)$ & $0.59(0.29,1.20)$ & 0.14 & & \\
\hline In sexual relationship & $37(52 \%)$ & $190(54 \%)$ & $0.91(0.55,1.52)$ & 0.72 & & \\
\hline Monogamous relations & $35(49 \%)$ & $181(52 \%)$ & $0.91(0.55,1.52)$ & 0.73 & & \\
\hline Current contraceptive use & $30(42 \%)$ & $115(33 \%)$ & $1.43(0.85,2.41)$ & 0.17 & & \\
\hline Ever gave birth & $56(79 \%)$ & $304(87 \%)$ & $0.55(0.29,1.06)$ & 0.07 & & \\
\hline \multicolumn{7}{|l|}{ Lifetime pregnancies } \\
\hline At least once & $23(33 \%)$ & $61(17 \%)$ & 1 & & 1 & \\
\hline$\geq 2$ & $47(67 \%)$ & $288(83 \%)$ & $0.43(0.24,0.77)$ & $<0.01$ & $0.41(0.21,0.78)$ & $<0.01$ \\
\hline \multicolumn{7}{|l|}{ Lifetime births } \\
\hline At least once & $45(63 \%)$ & $142(41 \%)$ & 1 & & & \\
\hline$\geq 2$ & $26(37 \%)$ & $207(59 \%)$ & $0.40(0.23,0.67)$ & $<0.001$ & & \\
\hline
\end{tabular}

VL: viral load.

Even though previous restrictive state laws that have explicitly limited the availability of ART services to PLWHIV [13] did contribute to the lack of access to fertility clinics within the US, low patient volume is the most common reason given by clinics for not providing services [31]. The perceived inaccessibility of these services by PLWHIV may contribute to the low number of clinics who actually treat patients from this population. There is a need for both provider and patient education to ensure the necessary provision of safe reproductive services to HIV-positive individuals. Healthcare practitioners need to provide accurate information regarding reproductive technology options and access to such services, while fertility service professionals need to be aware of the increasing demand for ART among PLWHIV and current recommendations regarding provision of treatment.

The limitations of our study include a potential for selection bias, as the survey used for this study was provided only in English and French and potentially limited to women literate in these two languages. As the survey was selfadministered to ensure privacy, the lack of added clarification by an interviewer may have contributed to certain questions being unanswered. The participants of this study were also relatively healthy, with high CD4 counts and good viral suppression on HAART, and may not represent the full spectrum of WLWHIV in Ontario. Finally, women who desire and intend pregnancy may be more motivated to complete a survey assessing reproductive intention. However, the large sample size in the study and the matching of study recruitment to the geographic distribution of HIV-positive women living in Ontario allowed for generalizability of study results to the population of WLWHIV in Ontario. A significant proportion of the study enrolment was also conducted using a community-based research model involving AIDS Service Organizations and WLWHIV in the recruitment coordination and process, which allowed the engagement of participants who do not usually partake in research.

Our findings indicate WLWHIV of reproductive age living in Ontario, Canada both desire and need to receive ART for safe pregnancy planning and conception and view healthcare providers as the main source of information regarding reproductive options. This study continues a series of assessments intended to guide the development of Canadian national guidelines on safer pregnancy planning and conception, as well as provincial and national HIV pregnancy planning and fertility programs. Potential future areas of research include an exploration of healthcare provider attitudes towards fertility and pregnancy for HIV-positive individuals as well as exploration of potential regional differences in their reproductive needs. To fully assess the reproductive needs of PLWHIV, similar research is also being considered for the population of men living with HIV.

\section{Acknowledgments}

The authors would like to thank the AIDS Service Organization staff and research coordinators (Melissa Mandool, Laura Puri, Sarah Culgin, Sharon Fair, Michele Ellis, Nancy McFarland, Anja McNeil, Linda Moran, Heather McDougall, Adriana D’Aquila, Arshia Ali, Myrle Chambers, Paula Havill, Maureen Kitscha, Margaret Howell, Leanne De Souza, Sue Hranilovic, Jennifer Hoffman, Nancy Lamoureux, Jenna Ekborn, and Elaine Lefaive) for their dedication to this project, the members of the Project Advisory Committee for their expertise, and the participants, whose participation made this study possible. This work was supported by a grant from CANFAR, the Canadian Foundation for AIDS Research, and the Ontario Ministry of Health and LongTerm Care, AIDS Bureau. The funders had no role in study 
TABLE 4: Participant responses to questions related to perception of and knowledge of ART.

\begin{tabular}{lc}
\hline Perception of ART & Total $(n=500)$ \\
\hline Open to medical techniques & \\
Strongly agree/agree & $285(59 \%)$ \\
Neither & $68(14 \%)$ \\
Strongly disagree/disagree & $133(27 \%)$ \\
Can go to sperm bank & \\
Strongly agree/agree & $192(39 \%)$ \\
Neither & $148(30 \%)$ \\
Strongly disagree/disagree & $153(31 \%)$ \\
Have tried to access sperm from a sperm bank & $8(2 \%)$ \\
\hline Knowledge of ART & Total $(n=500)$ \\
\hline Important sources of information regarding ART: & \\
A friend & $73(15 \%)$ \\
A family member & $56(12 \%)$ \\
A physician & $357(74 \%)$ \\
Other health care professionals & $232(48 \%)$ \\
Nobody & $48(10 \%)$ \\
Resources needed to help with decision to & \\
become pregnant: & $102(24 \%)$ \\
Information booklets and publications on & $213(50 \%)$ \\
becoming pregnant & \\
To talk to a health professional with fertility & $254(59 \%)$ \\
expertise & $113(26 \%)$ \\
To talk someone with fertility expertise & $155(36 \%)$ \\
Arom my community & \\
Access to a fertility clinic & \\
An obstetrician/gynecologist & \\
Access to sperm bained midwife & \\
\hline
\end{tabular}

design, data collection and analysis, decision to publish, or preparation of the paper. Additionally, a number of investigators are the recipients of salary support from the Canadian Institutes of Health Research (M. R. Loutfy). J. M. Raboud was supported by a Career Scientist Award from the Ontario HIV Treatment Network.

\section{References}

[1] F. J. Palella Jr., R. K. Baker, A. C. Moorman et al., "Mortality in the highly active antiretroviral therapy era: changing causes of death and disease in the HIV outpatient study," Journal of Acquired Immune Deficiency Syndromes, vol. 43, no. 1, pp. 2734, 2006.

[2] Perinatal HIV Guidelines Working Group, "Public Health Service Task Force Recommendations for Use of Antiretroviral Drugs in Pregnant HIV-1- Infected Women for Maternal
Health and Interventions to Reduce Perinatal HIV-1 Transmission in the United States," National Institute of Health, 2009, http://aidsinfo.nih.gov/contentfiles/PerinatalGL.pdf.

[3] Health Canada, "HIV/AIDS Epi Update. The Surveillance and Risk Assessment Division of the Centre for Infectious Disease Prevention and Control Public Health Agency of Canada," November 2007, http://www.phac-aspc.gc.ca/aidssida/publication/epi/pdf/epi2007_e.pdf.

[4] C. Gilling-Smith, J. D. M. Nicopoullos, A. E. Semprini, and L. C. G. Frodsham, "HIV and reproductive care-a review of current practice," BJOG: An International Journal of Obstetrics and Gynaecology, vol. 113, no. 8, pp. 869-878, 2006.

[5] National HIV Pregnancy Planning Guidelines Working Group, "National HIV Pregnancy Planning Guidelines Development Report," Canadian HIV Fertility Program, Women \& HIV Research Program, October 2011, http://www.ohtn .on.ca/pdf/NHPPG_Report.pdf.

[6] L. C. G. Frodsham, F. Boag, S. Barton, and C. Gilling-Smith, "Human immunodeficiency virus infection and fertility care in the United Kingdom: demand and supply," Fertility and Sterility, vol. 85, no. 2, pp. 285-289, 2006.

[7] A. Fakoya, H. Lamba, N. Mackie et al., "British HIV Association, BASHH and FSRH guidelines for the management of the sexual and reproductive health of people living with HIV infection 2008," HIV Medicine, vol. 9, no. 9, pp. 681-720, 2008.

[8] M. Weigel, "German-Austrian guidelines for diagnosis and treatment of HIV-discordant couples who wish to have children," Deutsche Medizinische Wochenschrift, vol. 128, supplement, pp. S32-S35, 2003.

[9] J. Guibert, M. Leruez-Ville, E. Dulioust et al., "Assisted procreation technology and people with HIV," Presse Medicale, vol. 37, no. 6, pp. 998-1006, 2008.

[10] A. Tandler-Schneider, U. Sonnenberg-Schwan, A. Gingelmaier et al., "Diagnostics and treatment of HIV-affected couples who wish to have children," European Journal of Medical Research, vol. 13, no. 12, pp. 546-551, 2008.

[11] J. Milliez, "Pregnancy and HIV-positive patients. FIGO Committee for the Ethical Aspects of Human Reproduction and Women's Health," International Journal of Gynecology and Obstetrics, vol. 107, no. 1, pp. 77-78, 2009.

[12] American Society for Reproductive Medicine Ethics Committee, "ASRM Ethics Committee Report-human immunodeficiency virus and infertility treatment," Fertility and Sterility, vol. 94, no. 1, pp. 11-15, 2010.

[13] N. Barnhart, M. Shannon, S. Weber, and D. Cohan, "Assisted reproduction for couples affected by human immunodeficiency virus in California," Fertility and Sterility, vol. 91, no. 4, pp. S1540-S1543, 2009.

[14] S. V. Thackway, V. Furner, A. Mijch et al., "Fertility and reproductive choice in women with HIV-1 infection," AIDS, vol. 11, no. 5, pp. 663-667, 1997.

[15] V. Savasi, C. Lanzani, T. Perscio et al., "Pregnancy by self insemination in women infected by HIV-1," in Proceedings of the 57th Annual Meeting of the American Society for Reproductive Medicine: Fertility and Sterility, vol. 76, supplement 3, p. 349, October 2001.

[16] M. G. Hull, C. M. Glazener, N. J. Kelly, D. I. Conway, P. A. Foster, R. A. Hinton et al., "Population study of causes, treatment, and outcome of infertility," British Medical Journal, vol. 291, no. 6510, pp. 1693-1697, 1985.

[17] K. L. Irwin, A. C. Moorman, M. J. O’Sullivan et al., "Influence of human immunodeficiency virus infection on pelvic inflammatory disease," Obstetrics and Gynecology, vol. 95, no. 4, pp. 525-534, 2000. 
[18] E. A. Bukusi, C. R. Cohen, C. E. Stevens et al., "Effects of human immunodeficiency virus 1 infection on microbial origins of pelvic inflammatory disease and on efficacy of ambulatory oral therapy," American Journal of Obstetrics and Gynecology, vol. 181, no. 6, pp. 1374-1381, 1999.

[19] E. Kalu, R. Wood, M. Vourliotis, and C. Gilling-Smith, "Fertility needs and funding in couples with blood-borne viral infection," HIV Medicine, vol. 11, no. 1, pp. 90-93, 2010.

[20] R. E. Frankel, P. A. Selwyn, J. Mezger, and S. Andrews, "High prevalence of gynecologic disease among hospitalized women with human immunodeficiency virus infection," Clinical Infectious Diseases, vol. 25, no. 3, pp. 706-712, 1997.

[21] S. D. Harlow, P. Schuman, M. Cohen et al., "Effect of HIV infection on menstrual cycle length," Journal of Acquired Immune Deficiency Syndromes, vol. 24, no. 1, pp. 68-75, 2000.

[22] J. D. Sobel, "Gynecologic infections in human immunodeficiency virus-infected women," Clinical Infectious Diseases, vol. 31, no. 5, pp. 1225-1233, 2000.

[23] J. R. Glynn, A. Buvé, M. Caraël et al., "Decreased fertility among HIV-1-infected women attending antenatal clinics in three African cities," Journal of Acquired Immune Deficiency Syndromes, vol. 25, no. 4, pp. 345-352, 2000.

[24] M. R. Loutfy, T. A. Hart, S. S. Mohammed et al., "Fertility desires and intentions of HIV-positive women of reproductive age in Ontario, Canada: a cross-sectional study," PLoS ONE, vol. 4, no. 12, Article ID e7925, pp. 1-10, 2009.

[25] B. Nattabi, J. Li, S. C. Thompson, C. G. Orach, and J. Earnest, "A systematic review of factors influencing fertility desires and intentions among people living with HIV/AIDS: implications for policy and service delivery," AIDS and Behavior, vol. 13, no. 5, pp. 949-968, 2009.

[26] S. Finocchario-Kessler, M. D. Sweat, J. K. Dariotis et al., "Understanding high fertility desires and intentions among a sample of urban women living with HIV in the United States," AIDS and Behavior, vol. 14, no. 5, pp. 1106-1114, 2010.

[27] S. Kanniappan, M. J. Jeyapaul, and S. Kalyanwala, "Desire for motherhood: exploring HIV-positive women's desires, intentions and decision-making in attaining motherhood," AIDS Care, vol. 20, no. 6, pp. 625-630, 2008.

[28] G. S. Ogilvie, A. Palepu, V. P. Remple et al., "Fertility intentions of women of reproductive age living with HIV in British Columbia, Canada," AIDS, vol. 21, no. 1, pp. S83-S88, 2007.

[29] N. L. Stanwood, S. E. Cohn, J. R. Heiser, and M. Pugliese, "Contraception and fertility plans in a cohort of HIV-positive women in care," Contraception, vol. 75, no. 4, pp. 294-298, 2007.

[30] S. M. Craft, R. O. Delaney, D. T. Bautista, and J. M. Serovich, "Pregnancy decisions among women with HIV," AIDS and Behavior, vol. 11, no. 6, pp. 927-935, 2007.

[31] J. A. Stanitis, D. R. Grow, and H. Wiczyk, "Fertility services for human immunodeficiency virus-positive patients: provider policy, practice, and perspectives," Fertility and Sterility, vol. 89, no. 5, pp. 1154-1158, 2008.

[32] K. Peltzer, L. W. Chao, and P. Dana, "Family Planning among HIV positive and negative Prevention of Mother to Child Transmission (PMTCT) clients in a resource poor setting in South Africa," AIDS and Behavior, vol. 13, no. 5, pp. 973-979, 2009.

[33] P. Oosterhoff, N. T. Anh, N. T. Hanh, P. N. Yen, P. Wright, and A. Hardon, "Holding the line: family responses to pregnancy and the desire for a child in the context of HIV in Vietnam," Culture, Health and Sexuality, vol. 10, no. 4, pp. 403-416, 2008.
[34] A. A. Nóbrega, F. A. S. Oliveira, M. T. G. Galvão et al., "Desire for a child among women living with HIV/AIDS in northeast Brazil," AIDS Patient Care and STDs, vol. 21, no. 4, pp. 261267, 2007.

[35] L. Myer, C. Morroni, and K. Rebe, "Prevalence and determinants of fertility intentions of HIV-infected women and men receiving antiretroviral therapy in South Africa," AIDS Patient Care and STDs, vol. 21, no. 4, pp. 278-285, 2007.

[36] D. J. Smith and B. C. Mbakwem, "Life projects and therapeutic itineraries: marriage, fertility, and antiretroviral therapy in Nigeria," AIDS, vol. 21, no. 5, pp. S37-S41, 2007.

[37] D. Cooper, J. Harries, and L. Myer, "Life is still going on': reproductiveintentions among HIV-positive women and men in South Africa," Social Science and Medicine, vol. 65, no. 2, pp. 274-283, 2007.

[38] C. Chama, J. Morrupa, and W. Gashau, "Sex and reproduction among HIV-infected people in Maiduguri, Nigeria," Journal of Obstetrics and Gynaecology, vol. 27, no. 8, pp. 812-815, 2007.

[39] S. Nakayiwa, B. Abang, L. Packel et al., "Desire for children and pregnancy risk behavior among HIV-infected men and women in Uganda," AIDS and Behavior, vol. 10, no. 7, pp. S95S104, 2006.

[40] O. T. Oladapo, O. J. Daniel, O. L. Odusoga, and O. AyoolaSotubo, "Fertility desires and intentions of HIV-positive patients at a suburban specialist center," Journal of the National Medical Association, vol. 97, no. 12, pp. 1672-1681, 2005.

[41] C. Baek and N. Rutenberg, Addressing the Family Planning Needs of HIV Positive PMTCT Clients: Baseline Findings from an Operations Research Study, Horizons Research Update, Washington, DC, USA, 2005.

[42] Y. Wesley, "Desire for children among black women with and without HIV infection," Journal of Nursing Scholarship, vol. 35, no. 1, pp. 37-43, 2003.

[43] A. L. Bedimo-Rung, R. A. Clark, J. Dumestre, J. Rice, and P. Kissinger, "Reproductive decision-making among HIVinfected women," Journal of the National Medical Association, vol. 97, no. 10, pp. 1403-1410, 2005.

[44] J. L. Chen, K. A. Phillips, D. E. Kanouse, R. L. Collins, and A. Miu, "Fertility desires and intentions of HIV-positive men and women," Family Planning Perspectives, vol. 33, no. 4, pp. 144-165, 2001.

[45] L. Doyal and J. Anderson, "'My fear is to fall in love again...' How HIV-positive African women survive in London," Social Science and Medicine, vol. 60, no. 8, pp. 1729-1738, 2005.

[46] S. J. Dyer, N. Abrahams, M. Hoffman, and Z. M. Van Der Spuy, "'Men leave me as I cannot have children': women's experiences with involuntary childlessness," Human Reproduction, vol. 17, no. 6, pp. 1663-1668, 2002.

[47] S. J. Dyer, N. Abrahams, N. E. Mokoena, and Z. M. van der Spuy, "You are a man because you have children': experiences, reproductive health knowledge and treatment-seeking behaviour among men suffering from couple infertility in South Africa," Human Reproduction, vol. 19, no. 4, pp. 960$967,2004$.

[48] N. F. Hacker, J. C. Gambone, and C. J. Hobel, Hacker and Moore'S Essentials of Obstetrics and Gynecology, Saunders Elsevier, Philadelphia, Pa, USA, 5th edition, 2010.

[49] L. Myer, R. J. Carter, M. Katyal, P. Toro, W. M. El-Sadr, and E. J. Abrams, "Impact of antiretroviral therapy on incidence of pregnancy among HIV-infected women in Sub-Saharan Africa: a cohort study," PLoS Medicine, vol. 7, no. 2, Article ID e1000229, 2010. 
[50] M. Maier, I. Andia, N. Emenyonu et al., "Antiretroviral therapy is associated with increased fertility desire, but not pregnancy or live birth, among HIV+ women in an early HIV treatment program in rural Uganda," AIDS and Behavior, vol. 13, no. 1, supplement, pp. S28-S37, 2009.

[51] S. López, O. Coll, M. Durban et al., "Mitochondrial DNA depletion in oocytes of HIV-infected antiretroviral-treated infertile women," Antiviral Therapy, vol. 13, no. 6, pp. 833838, 2008.

[52] M. H. Yudin, H. M. Shapiro, and M. R. Loutfy, "Access to infertility services in Canada for HIV-positive individuals and couples: a cross-sectional study," Reproductive Health, vol. 7, no. 1, article 7, 2010. 


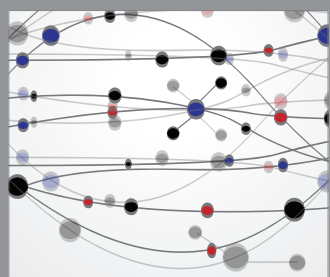

The Scientific World Journal
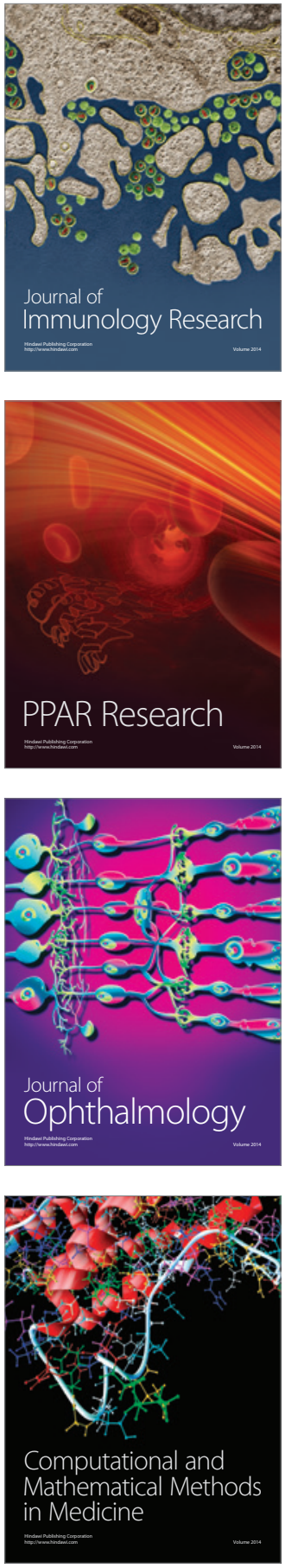

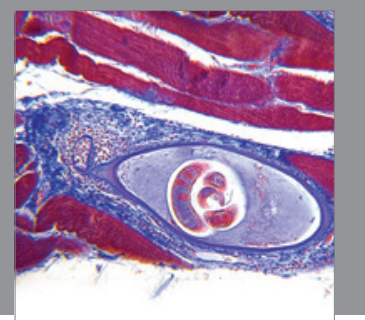

Gastroenterology

Research and Practice
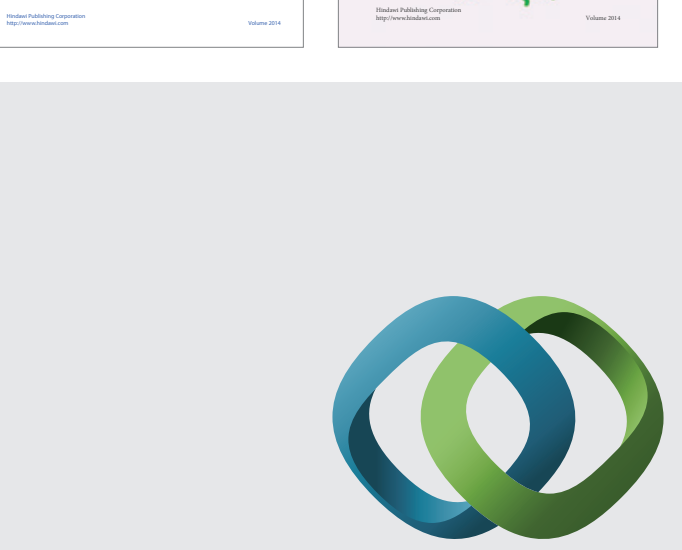

\section{Hindawi}

Submit your manuscripts at

http://www.hindawi.com
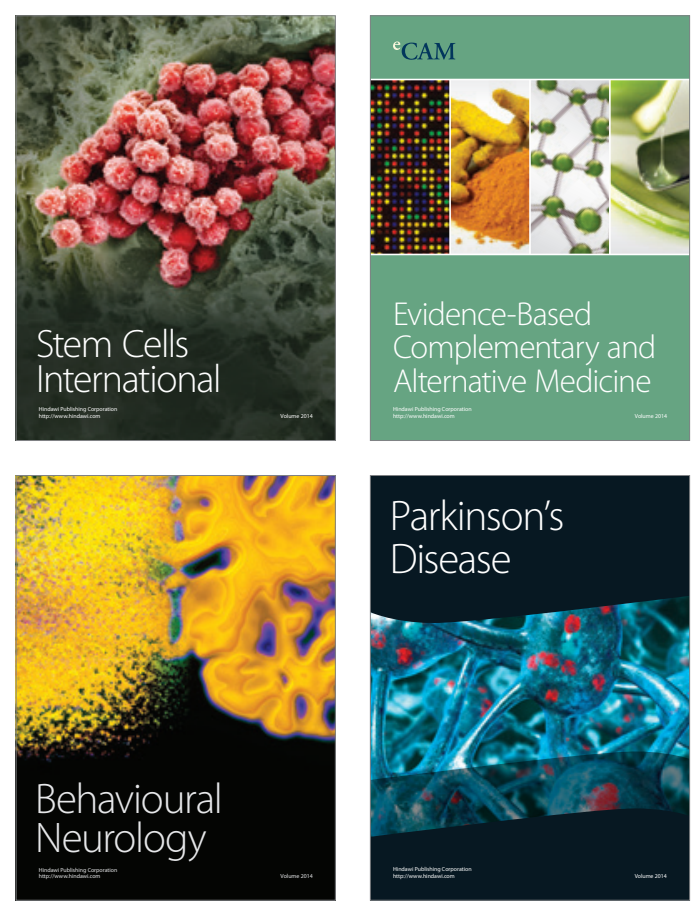

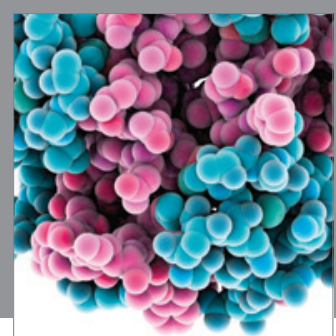

Journal of
Diabetes Research

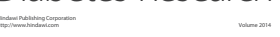

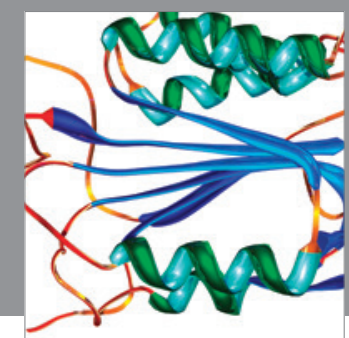

Disease Markers
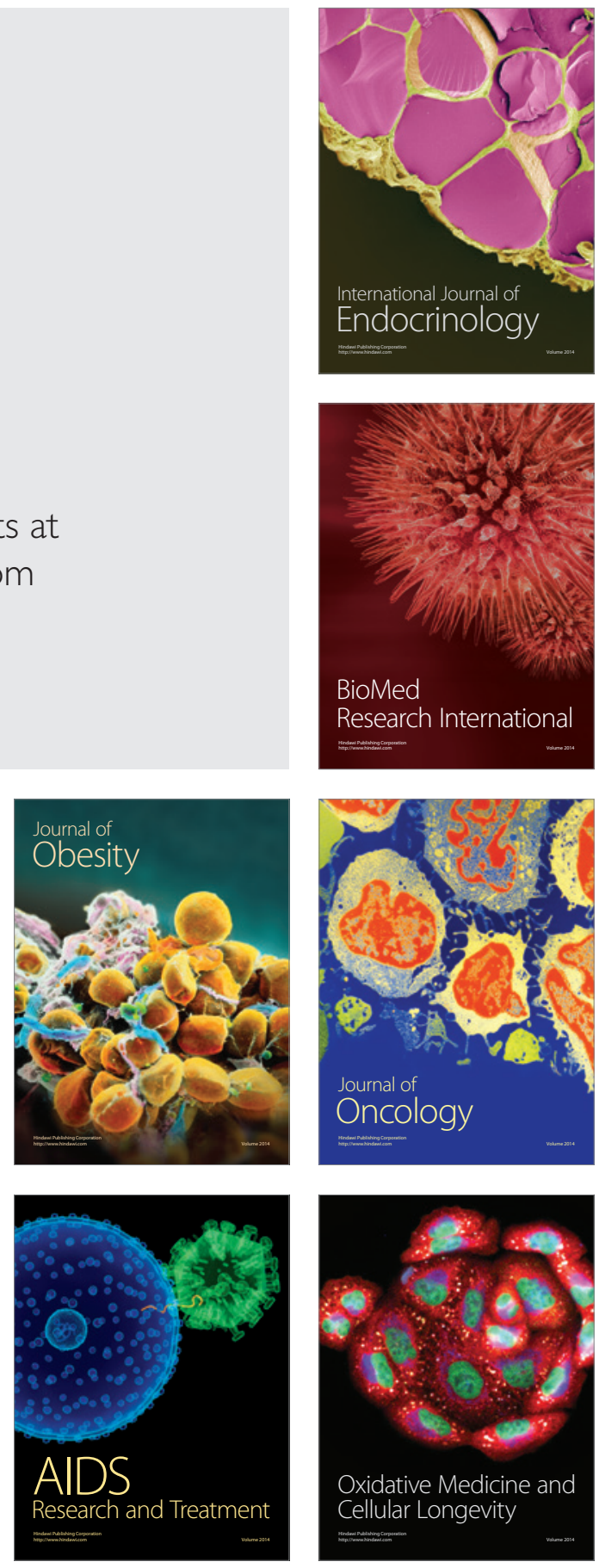